\title{
SAR focusing of P-band ice sounding data using back-projection
}

\author{
Kusk, Anders; Dall, Jørgen
}

Published in:

International Geoscience and Remote Sensing Symposium proceedings

Link to article, DOI:

10.1109/IGARSS.2010.5651038

Publication date:

2010

Document Version

Publisher's PDF, also known as Version of record

Link back to DTU Orbit

Citation (APA):

Kusk, A., \& Dall, J. (2010). SAR focusing of P-band ice sounding data using back-projection. In International Geoscience and Remote Sensing Symposium proceedings (pp. 4071-4074). IEEE.

https://doi.org/10.1109/IGARSS.2010.5651038

\section{General rights}

Copyright and moral rights for the publications made accessible in the public portal are retained by the authors and/or other copyright owners and it is a condition of accessing publications that users recognise and abide by the legal requirements associated with these rights.

- Users may download and print one copy of any publication from the public portal for the purpose of private study or research.

- You may not further distribute the material or use it for any profit-making activity or commercial gain

- You may freely distribute the URL identifying the publication in the public portal

If you believe that this document breaches copyright please contact us providing details, and we will remove access to the work immediately and investigate your claim. 


\title{
SAR FOCUSING OF P-BAND ICE SOUNDING DATA USING BACK-PROJECTION
}

\author{
Anders Kusk, Jørgen Dall \\ National Space Institute, DTU Space, Technical University of Denmark \\ Ørsteds Plads 348, 2800 Kongens Lyngby, Denmark, e-mail: ak@space.dtu.dk
}

\begin{abstract}
SAR processing can be applied to ice sounder data to improve along-track resolution and clutter suppression. This paper presents a time-domain back-projection technique for SAR focusing of ice sounder data. With this technique, variations in flight track and ice surface slope can be accurately accommodated at the expense of computation time. The back-projection algorithm can be easily parallelized however, and can advantageously be implemented on a graphics processing unit (GPU). Results from using the back-projection algorithm on POLARIS ice sounder data from North Greenland shows that the quality of data is improved by the processing, and the performance of the GPU implementation allows for very fast focusing.
\end{abstract}

Index Terms - SAR, radar, ice sounding, backprojection, GPU

\section{INTRODUCTION}

SAR processing is an established technique for providing improved along-track resolution and clutter suppression for coherent ice sounder systems. Published methods, e.g. [1][2], are usually based on frequency domain methods such as the range-Doppler algorithm, extended to account for the refraction at the air/ice interface. These methods are fast, but inherently apply block processing to speed up the processing. For this to work properly, assumptions must be made on both the flight track and the ice surface slope, both of which are usually modeled as linear within a certain along-track block size. Furthermore, methods such as the range-Doppler algorithm are not well-suited when the synthetic aperture becomes comparable to the target range, a situation that may well arise for airborne systems. A different approach is to use time-domain methods such as matched filtering or back-projection. These methods are computationally very intensive, but allows for more accurate accommodation of sensor motion and surface geometry. Direct back-projection (DBP) is well-known technique for focusing wideband SAR data, and fast implementations (FBP) also exist, with computational performance approaching that of frequency domain algorithms [3]. In the following, an approach for applying DBP to ice sounder data is described and tested on P-band ice sounder data acquired by ESA's POLARIS ice sounder. To reduce the computation time, the back-projection algorithm can be implemented on a graphics processing unit (GPU).

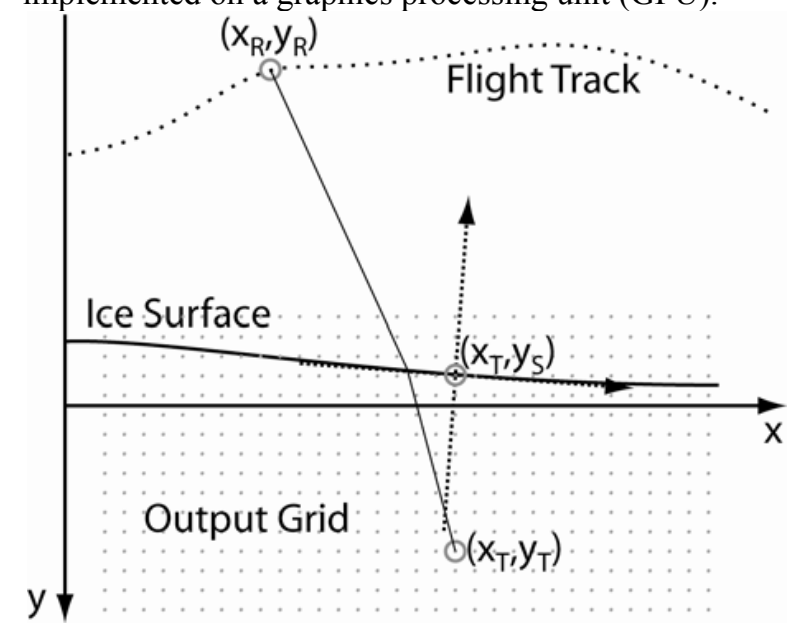

Figure 1 Ice sounder back-projection geometry

\section{ICE SOUNDER GEOMETRY}

The ice sounder geometry is illustrated in Figure 1. To perform SAR focusing and geocoding, knowledge of the flight track is required. This is usually measured by a combination of a GPS and an Inertial Navigation Unit (INU). Furthermore, the ice surface topography should be known. Depending on the radar operating mode (pulse length and range offset), this may be estimated from the sounding data itself, or by additional sensors, such as laser or radar altimeters. The POLARIS system provides a shallow/deep sounding mode, which alternates between short and long pulses, imaging the surface/top part of the ice, and the bedrock, respectively.

\section{BACK-PROJECTION ALGORITHM}

The DBP algorithm itself is simple, and can be described by[3]:

$$
s_{o}\left(x_{T}, y_{T}\right)=\sum_{\left|x_{R}-x_{T}\right|<L / 2} s_{i}\left[x_{R}, \tau_{r t}\right] \exp \left(j 2 \pi f_{C} \tau_{r t}\right)
$$

where $\left(x_{T}, y_{T}\right)$ is the output pixel position, $\left(x_{R}, y_{R}\right)$ is the sensor postion, $s_{o}\left(x_{T}, y_{T}\right)$ is the focused output pixel, $s_{i}(x, \tau)$ is the (complex baseband) input data matrix, ordered by 
along-track position and time delay, $L$ is the synthetic aperture length, $f_{C}$ is the radar center frequency, and $\tau_{r t}$ is the total round-trip delay from sensor to target, through air and ice. Thus for each output pixel, a summation is made over all input lines within the synthetic aperture. An optional weighting of the aperture can be performed to suppress sidelobes. The value of the input signal at each sensor position must be interpolated from the sampled data. The round-trip time delay, $\tau_{r t}$, is not straightforward to calculate, as it depends on the refractive properties of the ice. Assuming, however, a constant relative permittivity of the ice, $\varepsilon_{r}$, and a known flat (possibly tilted) ice surface the round-trip delay can be found by using Snell's law of refraction, resulting in a fourth order equation[2] which for each output pixel position, must be solved for all sensor positions within the aperture. With a limited aperture and a flat horizontal surface, however, a small-angle approximation can be applied, resulting in:

$$
\begin{gathered}
\tau_{r t}=\frac{2}{c}\left(r_{\text {air }}+\sqrt{\varepsilon_{r}} r_{i c e}\right) \approx \\
\frac{2}{c}\left(h \sqrt{1+\left(\frac{x_{R}-x_{T}}{h+d / \sqrt{\varepsilon_{r}}}\right)^{2}}+d \sqrt{\varepsilon_{r}+\left(\frac{x_{R}-x_{T}}{h+d / \sqrt{\varepsilon_{r}}}\right)^{2}}\right)
\end{gathered}
$$

where $c$ is the speed of light in air, $h$ is the sensor altitude over the ice and $d$ is the depth of the output pixel in the ice. For higher accuracy, an alternative is to tabulate the deviation between the approximation above and the actual fourth order equation solutions for a sufficiently dense grid of normalized $\left(x_{R}-x_{T}, d\right)$ combinations, normalizing by setting $h=1$. When the ice surface is sloped, one can, for each output along-track position, $x_{T}$, fit a line to the ice surface around $x_{T}$ and calculate the local surface height, $y_{S}$, and slope $\theta_{S}$. Then by doing a coordinate transformation (see also Figure 1):

$$
\left[\begin{array}{l}
x^{\prime} \\
y^{\prime}
\end{array}\right]=\left[\begin{array}{cc}
\cos \theta_{S} & \sin \theta_{S} \\
-\sin \theta_{S} & \cos \theta_{S}
\end{array}\right]\left[\begin{array}{l}
x-x_{T} \\
y-y_{S}
\end{array}\right]
$$

one can substitute $h=y_{R}^{\prime}, d=-y_{T}^{\prime}, x_{R}=x_{R}^{\prime}$, and $x_{T}=x_{T}^{\prime}$ when calculating $\tau_{r t}$, either by using the approximation above or a table lookup. The advantage of the DBP algorithm over frequency domain algorithms is that the variations in sensor flight track and surface height/slope can readily be accommodated and updated for each along-track position. Furthermore, the output grid can be selected arbitrarily (within the coverage of the data), and one can for example chose an output spacing constant in space rather than in time delay. The disadvantage of DBP is the high number of computations required

\section{IMPLEMENTATION}

The DBP algorithm described above is straightforward to implement on a PC. Due to the large number of computations involved, it is very time-consuming to focus long tracks, since for every output pixel, $L / \delta_{x}$ interpolations and phase multiplications are required, where $L$ is the aperture length and $\delta_{x}$ the along-track spacing of the input data. In addition to this, $\tau_{r t}$ must be calculated the same number of times. However, the DBP algorithm lends itself well to implementation on a GPU [4], since it can be parallelized to a large degree. In the implementation presented here, the GPU launches many threads in parallel, one for each output pixel. In one thread, each input line contributing to the synthetic aperture is processed sequentially, performing coordinate system transformation using navigation and surface height data, calculation of round-trip time to the output pixel, interpolation, phase correction, weighting, and summation. The interpolation step is performed by the GPU texture units, which provide very fast, albeit low-precision, linear interpolation of the input data. If necessary, to provide sufficiently accurate interpolation, the input data can be upsampled using FFT's prior to the linear interpolation, something which only needs to be done once for every input line.

\section{RESULTS}

\subsection{Focusing}

The DBP algorithm was applied to data acquired with the POLARIS ice sounder [5]. POLARIS is a fully polarimetric, airborne P-band ice sounder developed for ESA by DTU Space, and operates at $435 \mathrm{MHz}$, with a bandwidth up to 85 $\mathrm{MHz}$. The system uses a shallow/deep sounding mode, alternately transmitting short and long pulses to acquire full depth profile with sufficient dynamic range.

An example of focusing shallow channel data is shown in Figure 2. These data were acquired on the same flight as above, but with $85 \mathrm{MHz}$ bandwidth, near Upernavik in North Greenland. The ice thickness is around $600-800 \mathrm{~m}$. The altitude of the sensor over the ice $(610 \mathrm{~m}$ nominal $)$ was estimated from the location of the surface echoes (not shown on the figure), and this was used to estimate the local surface height and slope for each output along-track position. These data, together with the navigation data input served as input to the back-projection, which was carried out on the GPU. The along-track sample spacing (after online presuming) was approximately $1 \mathrm{~m}$, and a $200 \mathrm{~m}$ aperture was used for the back-projection. The focusing can be seen to improve the signal-to-noise ratio and resolution, compared to the raw data, while providing less speckle than the coherent averaging (which is essentially an unfocused SAR processing).

Figure 3 shows the results of DBP focusing of deep data acquired with $30 \mathrm{MHz}$ bandwidth, at the NEEM drilling site in Northern Greenland, in October 2009. The along-track sample spacing (after online presuming) was again $1 \mathrm{~m}$, and a $300 \mathrm{~m}$ aperture was used for the back-projection. where the same data processed using only incoherent averaging or coherent averaging are also shown. Again, the backprojection clearly improves the signal-to-noise ratio, compared to coherent averaging. 
(a)

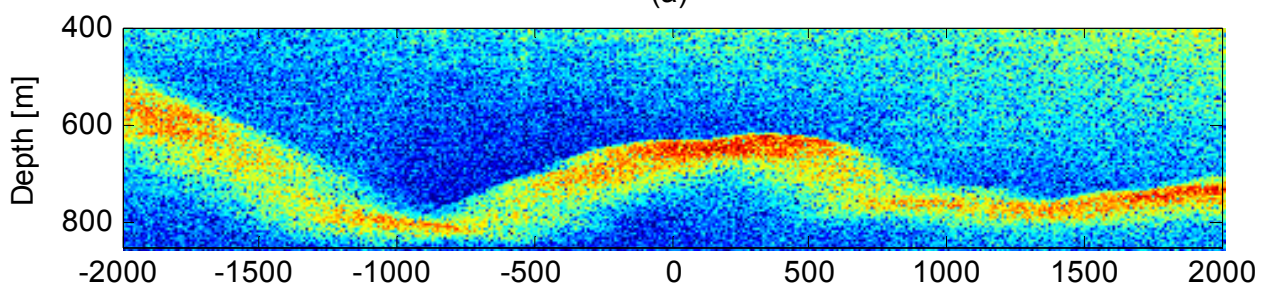

(b)

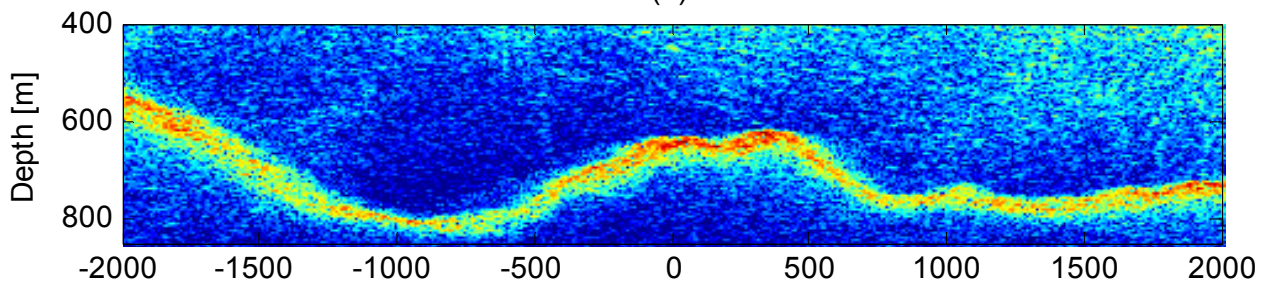

(c)

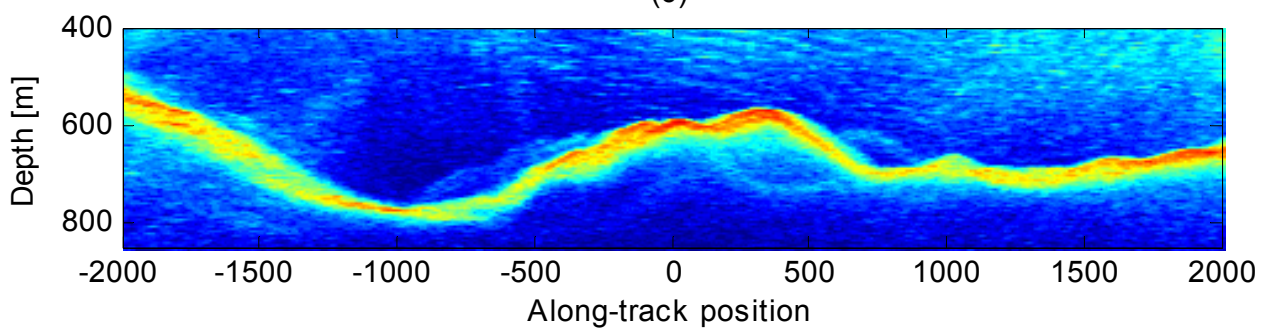

Figure 2 Bedrock near the ice edge, Upernavik in North East Greenland, (a) Raw data, (b) Coherent averaging (28 samples), (c) Back-projected, 200 m synthetic aperture, followed by 28 sample incoherent averaging

(a)

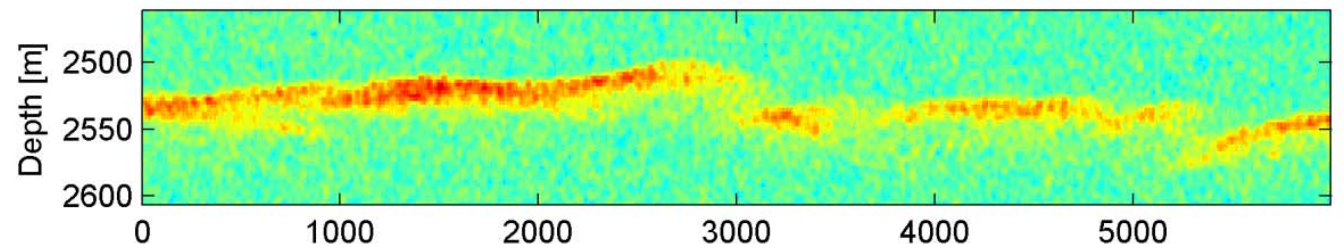

(b)
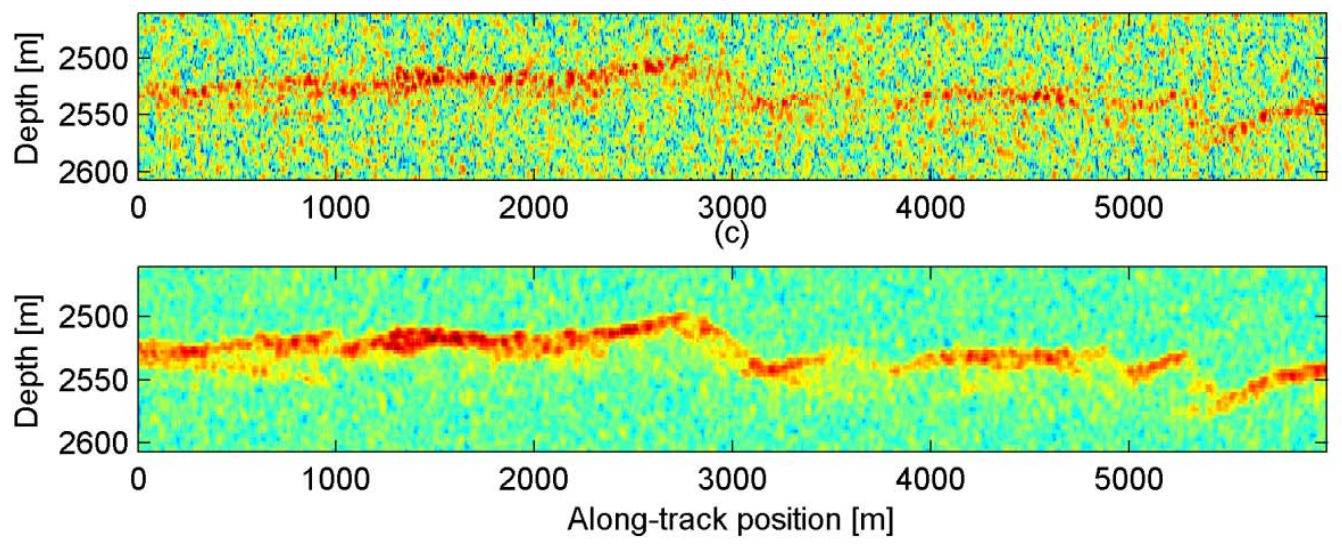

Figure 3 Bedrock at NEEM drilling site from POLARIS sensor, (a) Incoherent averaging (28 samples), (b) Coherent averaging (28 samples), (c) Back-projected, $300 \mathrm{~m}$ synthetic aperture, followed by 28 sample incoherent averaging 


\subsection{Computational Performance}

The SAR image on Figure 2(c) was focused using and NVidia GTX260 GPU. The focused image consists of $512 \mathrm{x}$ 5120 pixels. Round-trip calculation was done using the small-angle approximation, as this was accurate enough for the $200 \mathrm{~m}$ synthetic aperture of employed. With an input spacing of $1 \mathrm{~m}, 200$ input lines are processed for each output pixel, resulting in 524 million back-projections total. This was performed in $600 \mathrm{~ms}$ on the GPU, including data transfer to and from the PC memory, i.e. 870 million backprojections per second. With this processing speed, focusing of long tracks indeed become feasible, and real-time processing could also be feasible, as the focused data represent 64 seconds of data. In real-time, however, access to the necessary navigation and surface data may be limited.

\section{CONCLUSION}

The DBP algorithm is an interesting method for SAR focusing of airborne ice sounding data, since it is a timedomain algorithm, and thus allows an accurate accommodation of surface slopes, sensor flight track variations, and refraction at the air/ice interface. The results presented indicate that the algorithm does improve the along-track resolution and reduces clutter compared to basic processing like incoherent and coherent averaging. Also, due to its simple structure, the algorithm can be implemented in parallel on a GPU, resulting in very fast execution speed and allowing for processing of very long tracks. A comparison with other SAR focusing algorithms for ice-sounding has not been carried out yet, although this would indeed be interesting. Also the algorithm should be tested on data where a longer synthetic aperture is available, and also on more challenging data sets with more surface clutter.

\section{REFERENCES}

[1] Legarsky, J.J., Gogineni, S.P., Akins, T.L., "Focused synthetic aperture radar processing of ice-sounder data collected over the Greenland ice sheet”, IEEE Transactions on Geoscience and Remote Sensing, Vol. 39, Issue 10, pp. 2109-2117, Oct. 2001

[2] Heliere, F., Chung-Chi Lin, Corr, H., Vaughan, D., "Radio Echo Sounding of Pine Island Glacier, West Antarctica: Aperture Synthesis Processing and Analysis of Feasibility From Space", IEEE Transactions on Geoscience and Remote Sensing, Vol. 45, Issue 8, pp. 2573-2582, Aug. 2007

[3] Ulander, L.M.H., Hellsten, H., Stenstrom, G., "Syntheticaperture radar processing using fast factorized back-projection", IEEE Transactions on Aerospace and Electronic Systems, Vol. 39, Issue 3, pp 760-776, July 2003

[4] Blom, M., and Follo, P., "VHF SAR image formation implemented on a GPU", Proc. IGARSS 2005, Vol. 5, pp. 33523356,2005
[5] Dall, J. et. al, "ESA'S POLarimetric Airborne Radar Ice Sounder (POLARIS): design and first results", IET Radar, Sonar \& Navigation, Vol. 4, Issue 3, pp. 488-496, June 2010 